\title{
Alguns aspectos da vegetação da serra do Cachimbo
}

\author{
Eduardo Lleras ( ${ }^{*}$ ) \\ Joseph H. Kirkbride Jr. (**)
}

\section{Resumo}

Algumas observações sobre a vegetação da serra do Cachimbo, ao longo da BR-163, são apresentados aqui. A BR-163 foi aberta ao tráfego em outubro de 1976. Os solos da serra são basicamente quartzo-arenosos, com afloramentos esporádicos de arenito. A vegetação, descrita pelo RADAM como Cerrado, corresponde melhor, na sua maior parte, a uma vegetação de Campina. Os elementos da vegetação podem ser descritos como mistos, sendo que se apresentam elementos de cerrado, de campina e alguns conhecidos só dos campos do alto rio Negro e das Guianas.

\section{INTRODUÇÃo}

A vegetação da serra do Cachimbo é pouco conhecida. Até o presente, poucos pesquisadores tinham visitado aquela área e, geralmente, só atingiram porções restritas da serra. Entre eles, salientam-se Egler, que em 1960 coletou durante poucos dias na margem nor-ocidental da serra, no rio Cururu; Black, Pires e Wurdack, que em 1956 coletaram durante alguns dias nas vizinhanças da Base Aérea de Cachimbo e William Anderson que, em 1972 atingiu a mesma área visitada por Egler. Em Junhe de 1974, William A. Rodrigues de passagem por Cachimbo fez uma pequena coleta (27 espécimes) nas proximidades do aeroporto.

A tendência geral até agora foi considerar a vegetação da serra como Cerrado, assim está indicada nos Mapas do RADAM. Na figura 1 , podemos observar a localização geográfica da serra. Encontra-se dentro da Amazônia fitogeográfica, ainda se é certo que a porção sul está a poucos quilômetros da possível zona de transição entre a Amazônia e a vegetação do Planalto Central.

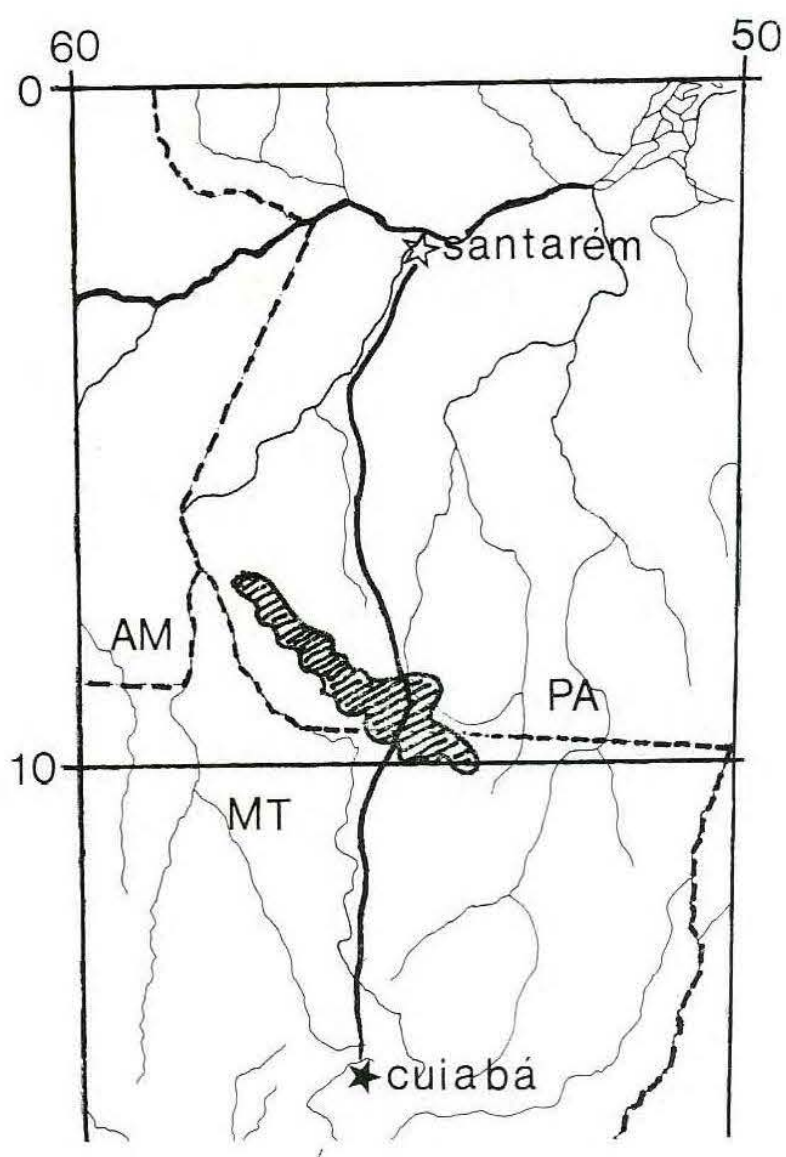

Figura 1. Localização geográfica da serra do $\mathrm{Ca}$ chimbo.

Em fevereiro-março de 1977, realizamos uma expedição à serra do Cachimbo, aproveitando a implantação da BR-163. A época do ano foi escolhida, assumindo que a vegetação, realmente, representava um tipo de cerrado, e sendo esta uma época de boa floração para o cerrado. Visamos aqui a apresentar uma descrição sucinta da vegetação.

$\left(^{\bullet}\right)$ - Instituto Nacional de Pesquisas da Amazônia, Manaus.

("*) - Dept. of Botany, The Smithsonian Institution, Washington D.C. 


\section{SOLos E ÁGUA}

Os solos da serra do Cachimbo são descritos na literatura (Soembrock, 1966; Eiten, 1975), como areias quártzicas; säo assim, solos pobres, de valor agrícola muito baixo ou nulo. Segundo o roteiro do $9 .^{\circ}$ Batalhão de Engenharia e Construção, existem três tipos de areia ao longo da estrada. O tipo mais comum é uma areia de coloração ligeiramente rósea, sendo que, esporadicamente, aparecem afloramentos de areia branca e cinza. A areia rósea tem sua origem, provavelmente, por meteorização de arenito vermelho, que é relativamente duro e resistente. A areia branca é originada de arenito branco, relativamente brando, e, segundo nossas observações, facilmente degradável. A areia cinza é originada de arenito relativamente duro (semelhante nesta característica ao arenito vermelho). Além das areias propriamente ditas, existem partes da serra nas quais aparecem afloramentos do próprio arenito.

Toda a água por nós observada era preta ou cristalina, sem material em suspensão.

\section{DESCRIÇÃO F́́SICA DA SERRA}

Os mapas do IBGE indicam a serra do $\mathrm{Ca}$ chimbo como uma área uniforme acima dos
500 metros (e menos de 600) sobre o nível do mar. Ao longo da BR-163, porém, observamos que a topografia da serra é bem acidentada. Podemos descrever a serra, ao longo da estrada, como terreno ondulado, com poucas partes planas. A altura máxima por nós registrada foi de 570 metros sobre o nível do mar, sendo que a mínima foi de 385 metros (as alturas foram tomadas ao longo da estrada). Estas alturas por si não apresentam grande diferença com o resto da BR-163 da serra até a encruzilhada desta e a BR-364 (Tabela 1, Fig. 2-A). Devemos pensar, então, que a serra do Cachimbo não está definida pela sua altura, e sim pelos seus solos e sua vegetação.

\section{VEgetação}

A serra do Cachimbo apresenta uma vegetação, ao longo da BR-163, tão variada quanto à topografia da região, e os solos da mesma (Tabela 2; Fig. 2-B). Em geral, as áreas mais baixas e, porém, mais úmidas apresentam vegetação relativamente mais alta. Assim, as margens dos córregos apresentam floresta de galeria. A medida que o terreno está mais exposto, o tamanho da vegetação vai diminuindo. Em nosso conceito, as formas básicas da vegetação são as mesmas encontradas nas vizi-

\begin{tabular}{|c|c|c|c|c|c|c|c|c|c|c|c|}
\hline $\begin{array}{l}\mathrm{Km} \text { na } \\
\text { BR-163 }\end{array}$ & $\begin{array}{c}\text { Tipo de } \\
\text { Vegetoşăo }\end{array}$ & $\begin{array}{l}\text { Altura } \\
m / \text { Sn } m\end{array}$ & $\begin{array}{l}\text { Km na } \\
\text { BR-163 }\end{array}$ & $\begin{array}{c}\text { Tipo de } \\
\text { Vegetoģäo }\end{array}$ & $\begin{array}{l}\text { Altura } \\
\mathrm{m} / \mathrm{sn} \mathrm{m}\end{array}$ & $\begin{array}{l}K m \text { na } \\
B R-163\end{array}$ & $\begin{array}{c}\text { Tipo de } \\
\text { Vegetoşâo }\end{array}$ & $\begin{array}{l}\text { Altura } \\
\mathrm{m} / \mathrm{Sn} \mathrm{m}\end{array}$ & $\begin{array}{l}\text { Km no } \\
\text { BR-163 }\end{array}$ & $\begin{array}{c}\text { Tipo de } \\
\text { Vegetaçäo }\end{array}$ & $\begin{array}{l}\text { Altura } \\
\mathrm{m} / \mathrm{Sn} \mathrm{m}\end{array}$ \\
\hline 170 & C. Cerr & & 310 & C. sujo & 460 & 450 & Fla, 5 & & 600 & Fla & 430 \\
\hline 180 & " & 560 & 320 & Pantano & 440 & 460 & $" .4$ & 310 & 610 & " & 500 \\
\hline 190 & - & & 330 & C. Cerr & & 470 & $\cdot$ & & 620 & " & 390 \\
\hline 200 & Cul & 490 & 340 & C. Cerr & 430 & 480 & - & & 630 & * & 360 \\
\hline 210 & Cerr & 430 & 350 & Brejo/Cerr, & 9 & 490 & - & & 632 & * & 460 \\
\hline 220 & Flb, 11 & 410 & 360 & Cerr & & 500 & Fla-capo & & 640 & * & 465 \\
\hline 230 & Cerr & 450 & 370 & * & & 510 & $\mathrm{Flb}$ & 380 & 650 & - & 360 \\
\hline 235 & C. Cerr & 530 & 380 & • & 400 & 520 & $\mathrm{Flb}$ & & 660 & $=2>169 \mathrm{~B}$ & B 350 \\
\hline 240 & Cerr $(s, s)$ & 530 & 390 & C. Cerr & 390 & 530 & $\mathrm{Fla}$ & 380 & 670 & $\bullet$ & \\
\hline 250 & C. Cerr/Cul & 515 & 400 & Cerr. 8 & & 540 & " & 365 & 680 & & 355 \\
\hline 260 & Flga/Cul, 10 & 420. & 410 & Cerradăo, 7 & & 550 & " & 380 & 690 & $\therefore 1$ & 320 \\
\hline 270 & C. Cerr & & 420 & $\cdot$ & & 560 & " & & 700 & $"$ & 330 \\
\hline 280 & $\cdot$ & 470 & 424 & $\cdot$ & 370 & 570 & - & 350 & 710 & J & 340 \\
\hline 290 & * & 460 & 430 & $\mathrm{Fla}$ & & 580 & $\cdot$ & & 720 & " & \\
\hline 300 & • & 460 & 440 & $\therefore, 6$ & 345 & 590 & $=3$ & & $\begin{array}{l}730 \\
740 \\
\end{array}$ &. & $\begin{array}{l}320 \\
320 \\
\end{array}$ \\
\hline
\end{tabular}

TABELA 1. Vegetação da BR-163 da serra do Cachimbo até a encruzilhada desta com a BR-364. C. Cerr, Campo Cerrado; Cerr?, Cerrado Sensu Stricto; Cerradão, Cerradão; C. sujo, Campo sujo; brejo, brejo; pantano, pantano; Cull, Terra cultivada; Fla, Floresta alta; Flb, Floresta baixa. 1 . Rio Peixoto de Azevedo; 2 , Córrego Batistăo; 3 . Rio Renato; 4 , Rio Calabi; 5 , Rio Nandico; 6 , Rio Celeste; 7 , Rio Lira; 8 . Rio Teles Pires; 9 . Rio Verde; 10. Rlo dos Patos; 11 , Rio Arinos; $169 \mathrm{~B}$, Reserva do 169 Batalhão de Caçadores 

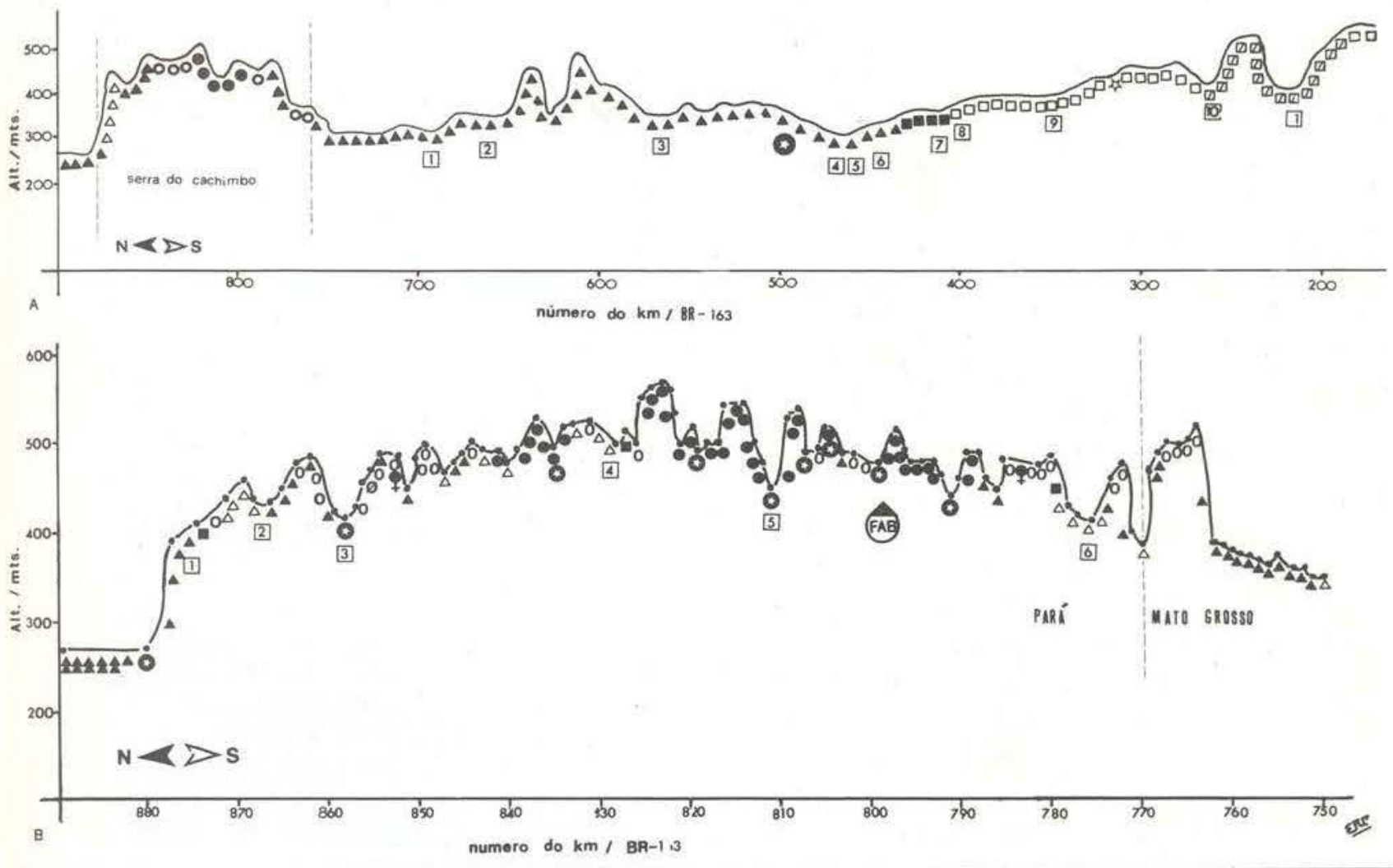

Figura 2. Perfil de Vegetação e alturas sobre o nível do Mar. A; BR-163 desde o Km. 890 até a encruzilhada com a BR-364. B; Detalhe da serra do Cachimbo. $\mathbf{A}$, Floresta Amazônica; $\mathbf{\Delta}$, Floresta alta; $\Delta$, Floresta baixa; O, Campinarana; - Campina; 구 , Floresta de galeria; $\mathbf{0}$, Cerradão; $\square$, Cerrado; $\square$, Terra cultivada; $\varnothing$. Capoeira de Campinarana; 7 , Capoeira de campina; $\hat{\imath}$, Pantano; F.A.B., desvio à Base Aérea do Cachimbo. Os números da figura A são os mesmos da tabela 1; Os da figura B correspondem a os da tabela 2.

nhanças de Manaus, quando em presença de areia. Ainda, se os tipos vegetacionais não são exatamente os mesmos, achamos que são fisionomicamente o suficiente semelhantes entre as duas regiões para não justificar terminologia distinta.

Fisionomicamente, definimos o tipo básico da vegetação como tipo "Campina". Dentro deste tipo básico temos diferenciado entre Campina aberta, Campinarana e Floresta sobre areia. Estes tipos são séries transicionais de um mesmo tipo básico de vegetação determinada pelo solo, água e outros fatores.

$\mathrm{Na}$ figura $2 \mathrm{~B}$ e Tabela 2 apresentamos um perfil de vegetação da serra ao longo da BR163. O levantamento foi feito, anotando quilômetro a quilômetro o tipo de vegetação presen. te. Além disto anotamos altura sobre o nível do mar. Nossas observações anemométricas foram ajustadas segundo a altura da base aérea da Serra do Cachimbo. A terminologia "Campina". Campinarana, etc. são relativamente subjetivas e baseadas na altura das árvores. Para dar uma margem de segurança à nossa terminologia, entramos em todos os tipos vegetacionais anotados aqui.

\section{CAMPINA (Fig. $3 \mathrm{~B}-7$ )}

O que temos considerado aqui como Campina apresenta uma fisionomia muito semeIhante a da Campina da Reserva INPA-SUFRAMA. É dominada por vegetação lenhosa formada tanto por árvores de 4 a 6 metros de altura, quanto arbustos tais como Pagamea guianensis Aubl. e Palicourea nitidella (Muell. Arg.) Standl. Na base de cada planta lenhosa, en- 
contra-se uma camada de material esponjoso formado por briófitas, líquens, folhas e humus. $\mathrm{Na}$ parte sombreada das ilhas maiores, encontramos plantas herbáceas tais como Schizaea elegans (Vahl) Sw. e Schizaea pennula Sw. (essas duas já conhecidas de campinas).

O tamanho das ilhas, como no caso das campinas perto de Manaus, é variável. As ảreas abertas também são variáveis, alcançando às vezes tamanhos até de $15 \times 15$ metros. Nas áreas abertas menores, encontram-se plan- tas herbáceas isoladas tais como Cassia, Vellozia e Paepalanthus.

Essas Campinas parecem ter uma composição florística que inclui elementos típicos de Campina, assim como elementos comuns do cerrado "sensu lato".

\section{CAMPINARANA (Fig. 3 B)}

Como no caso anterior, a fisionomia da Campinarana da serra do Cachimbo é bem semelhante a da Campina da Reserva INPA-

\begin{tabular}{|c|c|c|c|c|c|c|c|c|c|c|c|c|}
\hline $\begin{array}{l}\text { Km na } \\
\text { BR-163 }\end{array}$ & $\begin{array}{c}\text { Tipo de } \\
\text { Vegetaçäo }\end{array}$ & $\begin{array}{l}\text { Altura } \\
\mathrm{m} / \mathrm{Sn} \mathrm{m}\end{array}$ & $\begin{array}{l}\mathrm{Km} \text { na } \\
8 R-163\end{array}$ & $\begin{array}{c}\text { Tipo de } \\
\text { Vegetoçăo }\end{array}$ & & $\begin{array}{c}\text { Altura } \\
m / S n m\end{array}$ & $\begin{array}{r}\text { Km na } \\
\text { BR-163 }\end{array}$ & $\begin{array}{c}\text { Tipo de } \\
\text { Vegetaşão }\end{array}$ & $\begin{array}{c}\text { Altura } \\
m / S n m\end{array}$ & $\begin{array}{r}K m \text { na } \\
B R-163\end{array}$ & $\begin{array}{c}\text { Tipo de } \\
\text { Vegetoçăo }\end{array}$ & $\begin{array}{l}\text { Altura } \\
m / S n m\end{array}$ \\
\hline 750 & Fla & 350 & 785 & C'arana & & 480 & 820 & $\mathrm{Ca}$ & 520 & 855 & C'arana & 470 \\
\hline 751 & $\mathrm{Flb}$ & 350 & 786 & $\mathrm{Flb}$ & & 450 & 821 & $"$ & 500 & 856 & C'arana - capo & 460 \\
\hline 752 & $"$ & 360 & 787 & $"$ & & 460 & 822 & $"$ & 535 & 857 & C'arana & 430 \\
\hline 753 & $"$ & 360 & 788 & $\mathrm{Ca}$ & & 490 & 823 & $"$ & 570 & 858 & Flga, 3 & \\
\hline 754 & $"$ & & 789 & $"$ & & 490 & 824 & $"$ & 565 & 859 & $\mathrm{Flb}$ & 420 \\
\hline 755 & $"$ & 375 & 790 & $n$ & & 460 & 825 & $"$ & 555 & 860 & C'arana & 425 \\
\hline 756 & $"$ & 365 & 791 & Flga & & 440 & 826 & C'arana & 500 & 861 & /Flca & \\
\hline 757 & $"$ & 370 & 792 & $\mathrm{Ca}$ & & 465 & 827 & Flca & 515 & 862 & $\mathrm{Flb}$ & 486 \\
\hline 758 & $"$ & 375 & 793 & " & & 480 & 828 & Fla & 500 & 863 & C'arana & 480 \\
\hline 759 & " & 375 & 794 & $"$ & & 480 & 829 & $", 4$ & & 864 & $\mathrm{Flb}$ & \\
\hline 760 & $"$ & 380 & 795 & $n$ & & 480 & 830 & " & & 865 & $"$ & 450 \\
\hline 761 & $"$ & 385 & 796 & $n$ & & 490 & 831 & C'arana & 525 & 866 & $"$ & 440 \\
\hline 762 & Flb/C'arana & 385 & 797 & $"$ & & 515 & 832 & Fla & & 867 & $=2$ & \\
\hline 763 & $\mathrm{Flb}$ & & 798 & " & & & 833 & $\mathrm{Fla}$ & 520 & 868 & Fla & 440 \\
\hline 764 & C'arana & 520 & 799 & Flga & & 480 & 834 & $\mathrm{Ca}$ & 520 & 869 & $n$ & 460 \\
\hline 765 & $"$ & 505 & 800 & C'arana & & & '835 & $\mathrm{Ca} / \mathrm{Flga}$ & 495 & 870 & $"$ & \\
\hline 766 & $"$ & 500 & 801 & $"$ & & 490 & 836 & $\mathrm{Ca}$ & & 871 & $"$ & 440 \\
\hline 767 & $"$ & 500 & 802 & Flb & & 490 & 837 & " & 530 & 872 & C'arana & \\
\hline 768 & $\mathrm{Flb}$ & 490 & 803 & C'arana & & & 838 & $"$ & & 873 & Flca & \\
\hline 769 & $"$ & 470 & 804 & Flga & & & 839 & $"$ & 490 & 874 & $\mathrm{Flb}$ & 410 \\
\hline 770 & $\mathrm{Fla}$ & 385 & 805 & $\mathrm{Ca}$ & & 520 & 840 & Fla & 480 & 875 & $"$ & \\
\hline 771 & Flb & 400 & 806 & C'arana & & 495 & 841 & $\mathrm{Ca}$ & 490 & 876 & $=$ & \\
\hline 772 & C'arana & 475 & 807 & $\mathrm{Ca} / \mathrm{Flga}$ & & 490 & 842 & Fla & & 877 & " & 390 \\
\hline 773 & $"$ & 460 & 808 & $\mathrm{Ca}$ & & 540 & 843 & C'arana & 495 & 878 & $"$ & 350 \\
\hline 774 & Flb & & 809 & 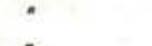 & & 530 & 844 & " & 500 & 879 & $n$ & \\
\hline 775 & Fla & & 810 & " & & & 845 & $\mathrm{Flb}$ & 490 & 880 & Flga & \\
\hline 776 & $", 6$ & 415 & 811 & $\mathrm{Ca} / \mathrm{Flga}$, & 5 & 450 & 846 & $"$ & 480 & 881 & $"$ & \\
\hline 777 & $"$ & 420 & 812 & $\mathrm{Ca}$ & & 480 & 847 & $\mathrm{Fla}$ & 470 & 882 & $"$ & 270 \\
\hline 778 & $"$ & 430 & 813 & " & & 505 & 848 & $"$ & & 883 & $=$ & \\
\hline 779 & Flca & & 814 & $n$ & & 545 & 849 & C'arana & 500 & 884 & Fla $]$ & \\
\hline 780 & C'arana & 485 & 815 & $"$ & & 545 & 850 & $"$ & 485 & 885 & $=$ & \\
\hline 781 & $"$ & 475 & 816 & $=$ & & 545 & 851 & Flb & 450 & 886 & . & \\
\hline 782 & 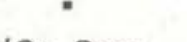 & & 817 & $=$ & & 500 & 852 & Ca-Capo & 485 & 887 & $=$ & \\
\hline 783 & 'Ca-Capo & & 818 & " & & 500 & 853 & C'arana & & 888 & $=$ & \\
\hline 784 & " & & 819 & Flga & & 495 & 854 & Flb & 490 & 889 & " & \\
\hline
\end{tabular}

TABELA 2. Ṽegetação da serra do Cachimbo ao longo da BR-163, com alturas sobre o nível do mar. Ca, Campina; $\mathrm{Ca}-\mathrm{Capo}$, Capoeira de Campina; C'arana, Campinarana; Flca, Floresta de Campina; Fla, Floresta alta; Flb, Floresta baixa; Flga, Floresta de Galeria. 1 . Serra de Curuá; 2 . Córrego Vermelho; 3 , Córrego Escorpião; 4 , Córrego Anta; 5 , Córrego São Bento; 6 , Córrego XV de Novembro 



Fig. 3 - A, brejo nas margens do rio Verde, Km. 350 da BR-163. B, margem sul da serra do Cachimbo. Floresta baixa na frente, Campina e Campinarana no espigão. 

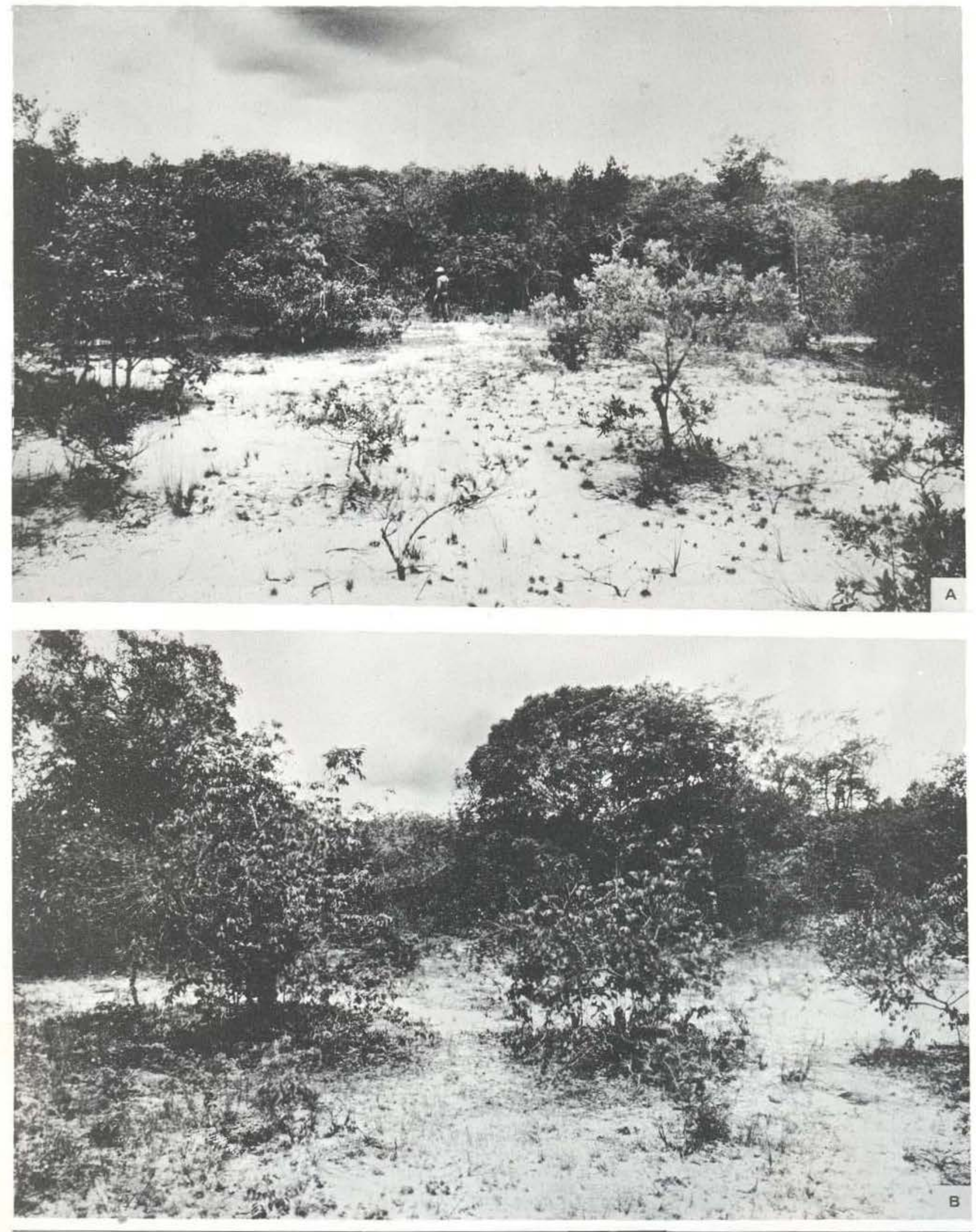

Fig. 4. Serra do Cachimbo. Aspectos da Campina (Km. 838-839 da BR-163). A, clareira grande. B, Ilhas de vegetação. 

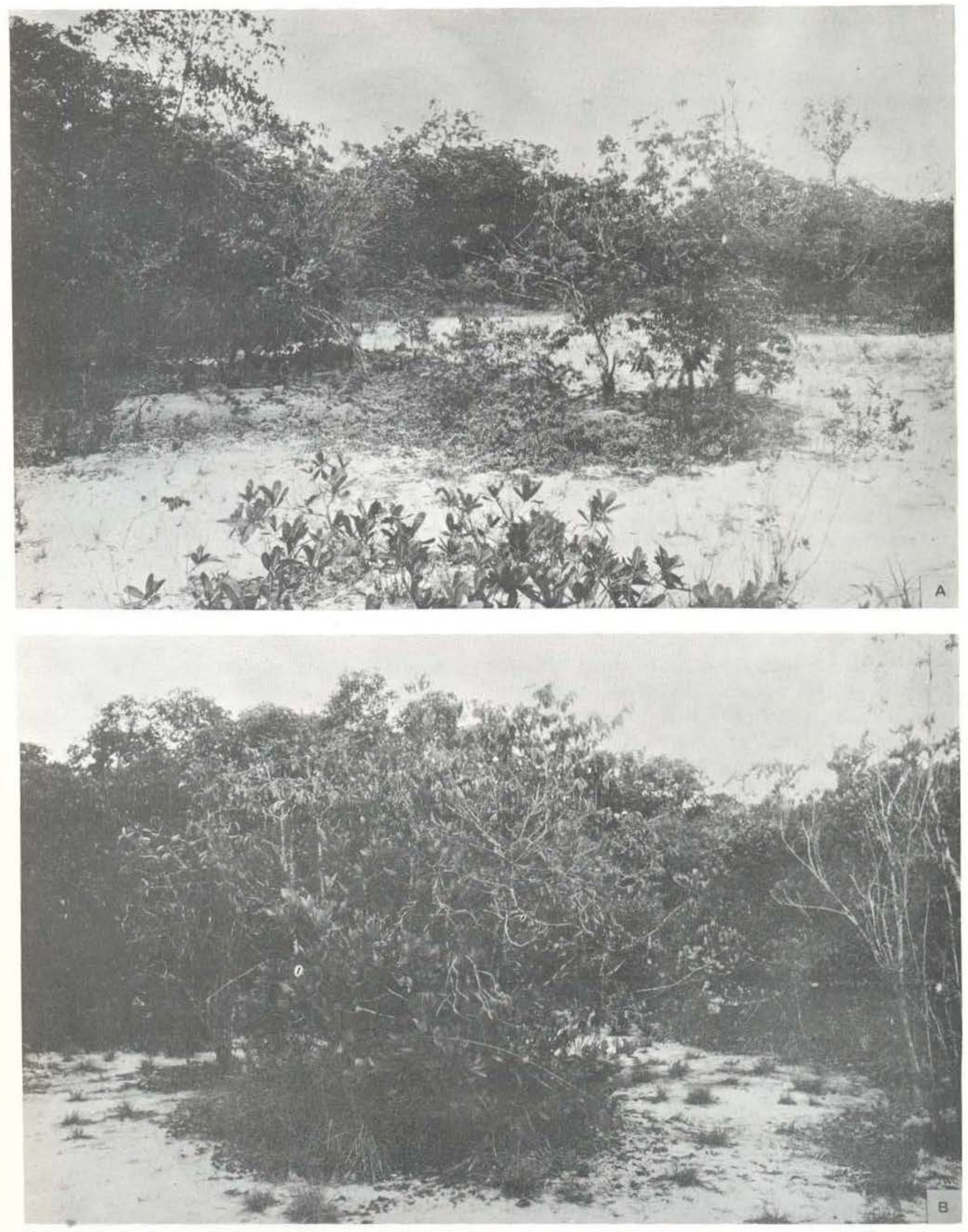

Fig. 5 - Comparação de ilhas de vegetação entre campinas. A, serra do Cachimbo; B, Reserva INPA-SUFRAMA, Km. 45 da BR-174. 


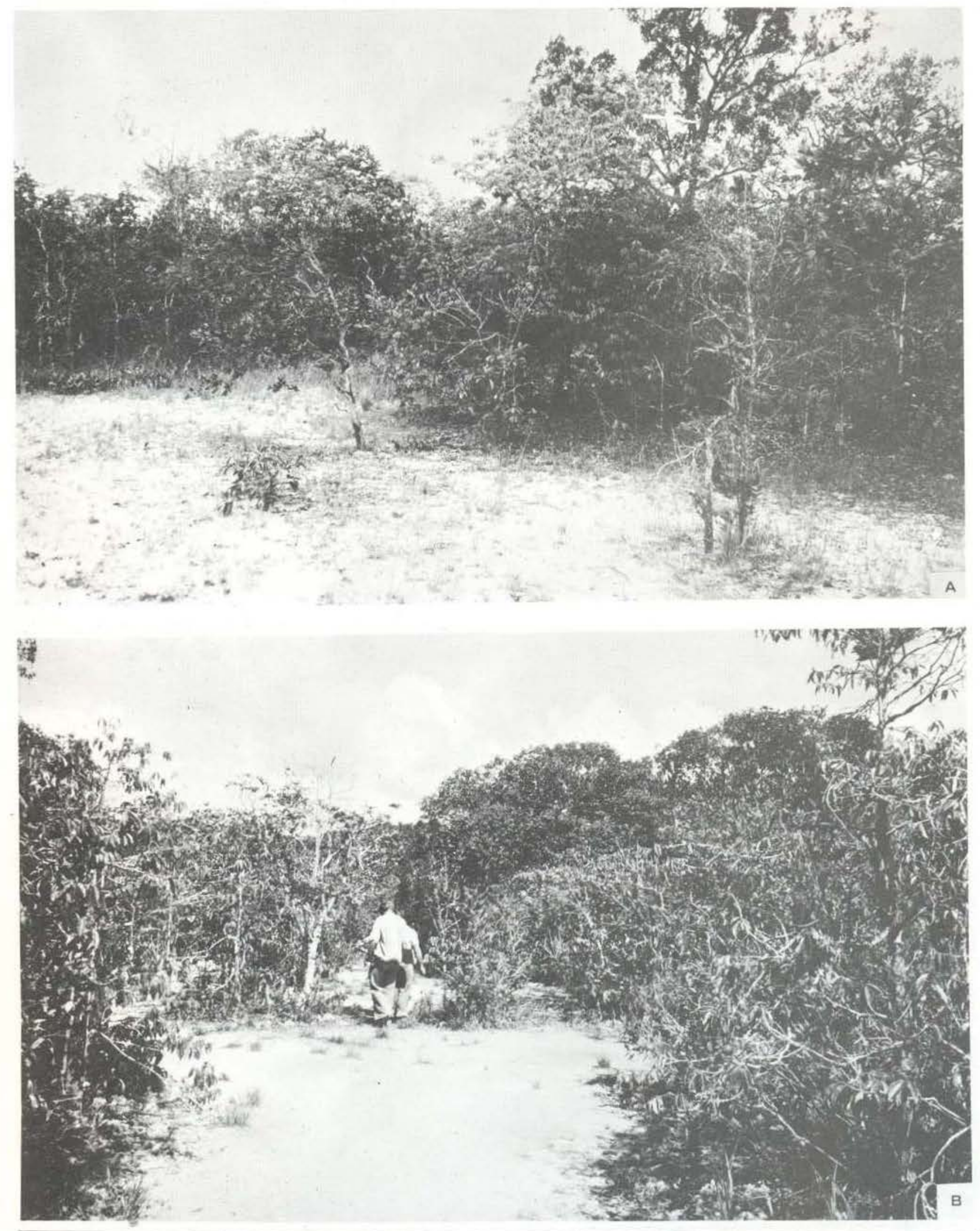

Fig. 6 - Comparação de clareiras entre campinas. A, serra do Cachimbo. B; Reserva do INPA-SUFRAMA, Km. 45 da BR-174. Note-se a maior abundância de plantas herbáceas na serra do Cachimbo. 
SUFRAMA. As árvores te maior porte (10 a 15 metros) apresentam ramificação perto do chã̃o, e copa bem extensa. Porém, nas áreas por nós visitadas, existe uma ausência quase total de epífitas, diferenciando do que ocorre na Reserva do INPA-SUFRAMA. Além de Pa. gamea guianensis, ocorre também Pagamea thyrsiflora Spr. ex Bth.

\section{FLORESTA SOBRE AREIA (Fig. $10 \mathrm{~A}$ )}

Assim como nos casos anteriores, esse tipo de Floresta encaixa bem dentro da definição utilizada na Reserva da Campina INPASUFRAMA; árvores com altura até 20 a 25 metros, de caule ereto, ramificado perto da copa, copas relativamente pequenas. O chão apresenta uma espessa camada de manta vegetal, que apresenta a mesma característica "esponjosa" observada por Anderson (comm. pessoal) na Reserva INPA-SUFRAMA.

\section{VEGETAÇÃO SOBRE ARENITO}

$\mathrm{Na}$ BR-163, esse tipo vegetacional encontra-se na margem norte da serra, crescendo no arenito. A vegetação é relativamente rala com arboretos alcançando no máximo 4 a 5 metros de altura. Algumas espécies são as mesmas da Campina, por ex. Pagamea guianensis), sendo que outras não são.

\section{VEGETAÇÃo SEMELHANTE AO CERRAdo (Fig. 9)}

Esse tipo vegetacional encontra-se perto da pista de pouso da serra do Cachimbo. Vista de longe, parece ser cerrado, campo cerrado ou campo sujo. De perto, difere do cerrado porque as plantas não apresentam caules tortuosos ou córtex grossa marcada pelo fogo. Encontra-se aqui, além de uma espécie de Hymenaea, Declieuxia fruticosa (Willd ex R. \& S.) O. Kuntze, e Rauwolfia weddelliana Muell. Arg., todas elas conhecidas de cerrado. Este tipo vegetacional é descrito por William Rodrigües (comun. pessoal) como campo rupestre, e por Murça Pires (Seminário apresentado no INPA) como campina rupestre.
VEGETAÇÃo SOBRE AREIA BRANCA (Fig. 8)

Este tipo vegetacional encontra-se às margens do córrego São Bento. Fisionomicamente é até certo ponto semelhante a um brejo. Porém, os elementos da vegetação tendem a ser maiores e mais emaranhados e densos, com solo relativamente úmido. Entre as espécies encontradas aqui, destacam-se Mauritia, Cassia, Utricularia, assim como várias espécies de Gramineae e Cyperaceae.

\section{Discussão}

A distribuição da vegetação de campina era conhecida até agora principalmente dos sistemas de drenagem do rio Negro, no Estado do Amazonas, e do rio Trombetas, no Estado do Pará (Comun. pessoal, Pedro Lisboa), e reportada, mas não confirmada, da parte norte do rio Teles Pires (Lisboa, comun. pessoal; 1976). Têm-se mostrado aqui, que também existe vegetação de campina na serra do Cachimbo. A vegetação de campina ao Norte dos rios Solimões e Amazonas tem sido adequadamente classificada, e a terminologia tem sido bem estabelecida por Lisboa (1975): Campina Amazônica da Amazônia Central, Campinarana Amazônica da Amazônia Central, Campina Amazônica do alto rio Negro, Campinarana Amazônica do alto rio Negro. Como foi indicado pela terminologia, as campinas estão em dois grupos principais: as da Amazônia Central e as do alto rio Negro. Um terceiro grupo pode agora ser adicionado: Campinas do Sul da Amazônia, tipifioadas pela vegetação da serra do Cachimbo. As campinas do rio Teles Pires ainda não são suficientemente conhecidas, para determinar qual o tipo de campina ou a que grupo de campina correspondem: porém, geograficamente, correspondem ao terceiro grupo anotado aqui.

Os solos de todas as campinas estudadas até agora, correspondem a areias quártzicas (Regossolos). Duas hipóteses têm sido postuladas para explicar a origem destes solos: a primeira postula a deposição dos solos como material de arrastre por ação de água (Landim Comun. pessoal), sendo que a segunda proposta para explicar a origem do solo na Campi- 



Fig. 7 - Comparação dos substratos de ilhas de vegetação. A, serra do Cachimbo; B, Reserva INPA-SUFRAMA. Note-se a presença de Cladonia e de Shizaea (seta). 

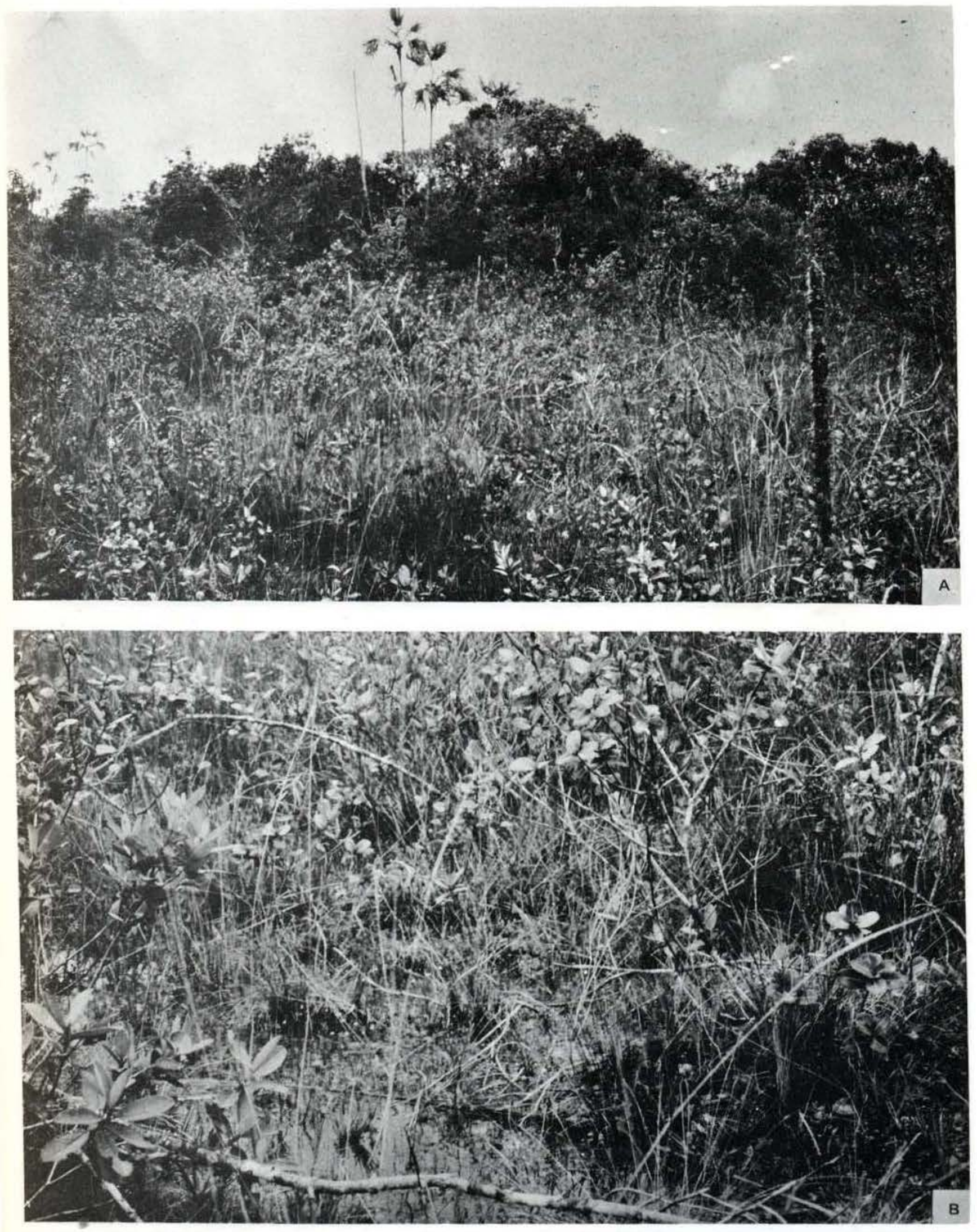

Fig. 8 - Serra do Cachimbo, vegetação sobre areia branca, córrego São Bento. A, vista geral, destacando-se a presença de Mauritia; B, detalhe da vegetação. 

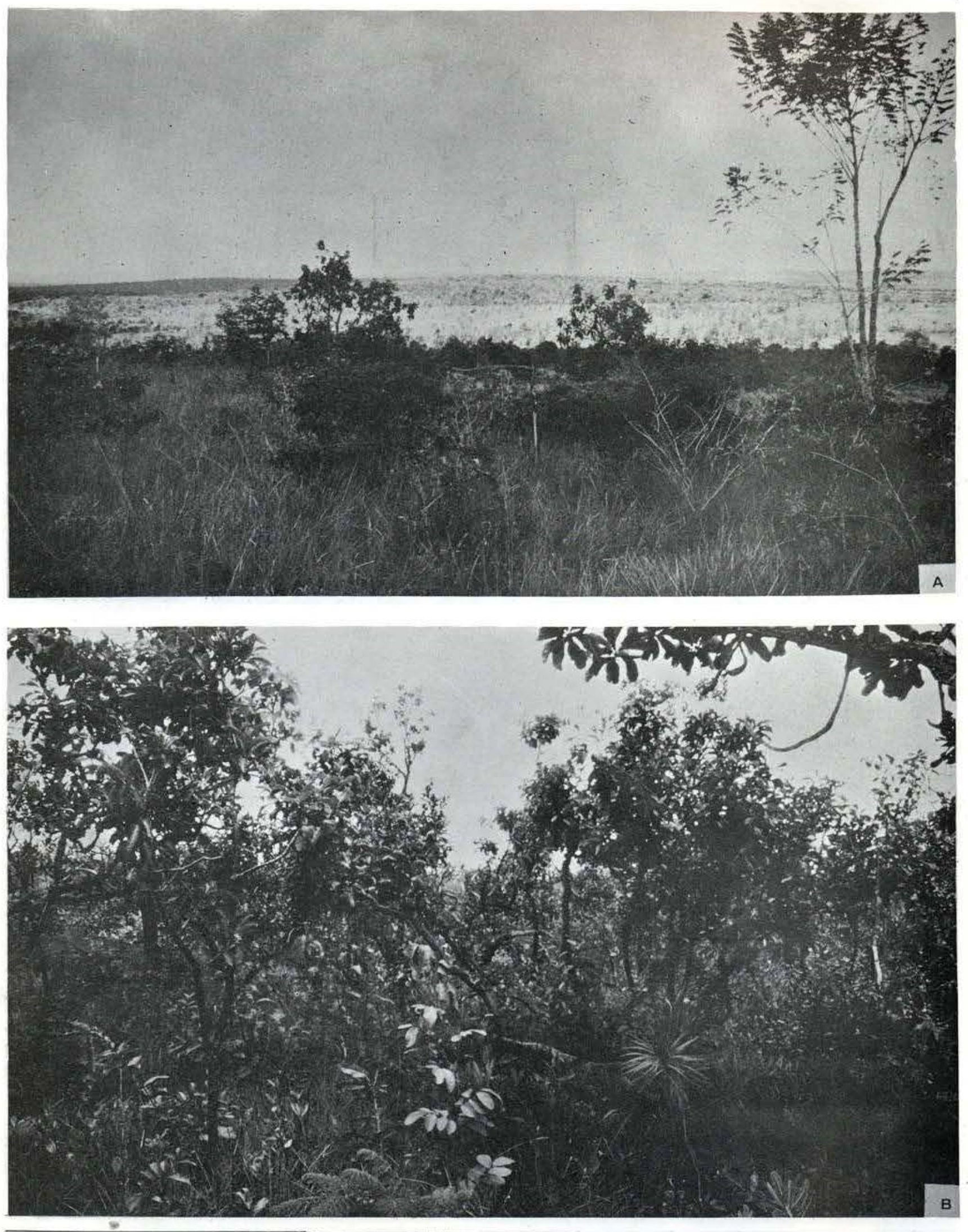

Fig. 9 - Comparação entre vegetação semelhante ao cerrado na margem da pista aérea de Cachimbo (A), com campo cerrado (B) no $\mathrm{Km} 383$ da BR-163 

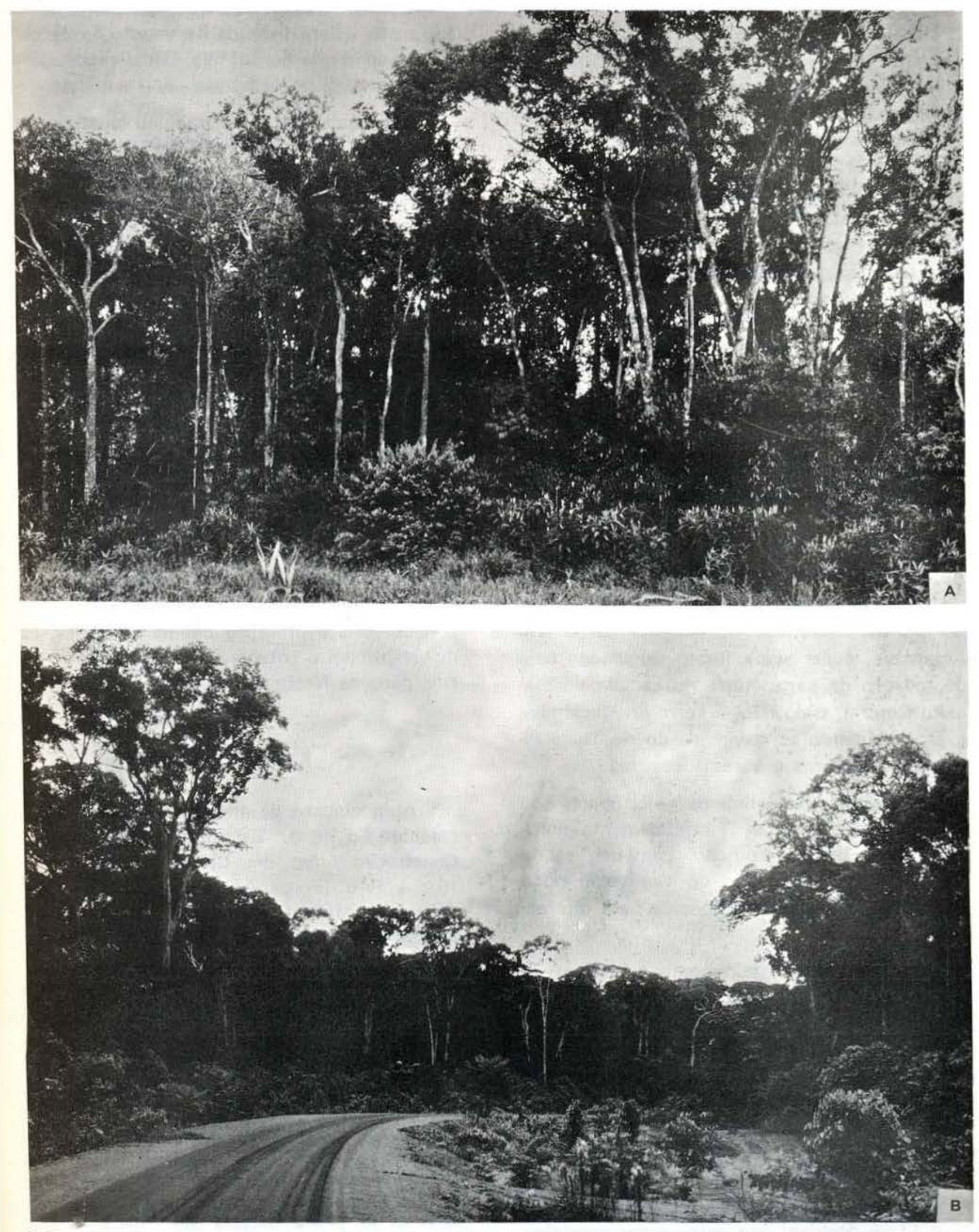

Fig. $10-$ A, floresta baixa da margem sul da serra do Cachimbo. B, Floresta amazônica ao norte da serra (Km. 890 da BR-163). 
na das Pedras (Km. 146 da BR-174) por Holley \& Lleras, não publicada, postula a degradação "in situ" do arenito. A primeira hipótese explica adequadamente a formação dos solos para a maioria das campinas perto de Manaus. A segunda, com a presença óbvia e visível do material parental, tem sido considerado um caso excepcional. A serra do Cachimbo, que é uma das maiores campinas conhecidas, apresenta características formativas que sugerem formação "in situ" dos solos. É uma chapada de arenito provavelmente depositada como parte do escudo do Planalto Central, e isolada do resto do escudo devido à erosão

Coms todos os solos de campina são inicialmente originados por degradação de arenito, devemos postular aqui que os solos das campinas do alto rio Negro e da Amazônia Central foram originados por degradação do Escudo das Guianas e carregados pelos rios originados nele, e drenando na margem norte do rio Amazonas. Postula-se aqui a existência de um sistema análogo de campinas (Campinas do Sul da Amazônia) na margem sul do rio Amazonas, cujos solos foram originados pela degradação da parte Norte do Escudo do Planalto Central, e do qual a serra do Cachimbo, e provavelmente as campinas do rio Teles Pires, são primeiras a serem descritas.

Neste trabalho definimos as campinas sob uma base fisionômica. Floristicamente achamos muito dificil "tipificar" campina, sendo que um tipo fisionômico de vegetação pode apresentar misturas de espécies bem diferentes.

Em observações puramente subjetivas ao longo da BR-364 (Porto Velho-Cuiabá) e a BR163 , encontramos uma diferença notória entre a vegetação ao Norte e ao Sul de aproximadamente o paralelo 12 Sul. Esta faixa de transição já foi reportada por Toledo (1962), pela expedição da Royal Society (Askew et al, 1970a, 1970b, 1971) e por Eiten (1975) na BR158 , onde eles encontraram uma "área de transição" vegetacional situada entre os paralelos 12 e 13. Épossivel que entre estes paralelos esteja a faixa de transição entre a vegetação amazônica e a vegetação do planalto central.
E interessante notar que ao Norte desta faixa não existe indícios de vegetação de cerrado, sendo que ao Sul não existe reportagens de vegetação de campinas.

Os resultados deste trabalho mostram claramente o pouco que conhecemos da vegetação sobre areia da parte sul da Bacia do rio Amazonas. Precisamos de muito mais dados e mais coletas, antes de termos uma idéia verdadeiramente clara destes tipos vegetacionais. Inicialmente, será preciso realizar um levantamento fitossociológico exaustivo da serra do Cachimbo, incluindo estudos de solos, água, climatologia, etc.. Também, será necessário realizar expedições explorativas que permitam a localização de outras campinas (e outros tipos vegetacionais) lá existentes. Tanto as campinas do alto rio Negro quanto as da Amazônia Central, têm provado ser de grande interesse tanto fitossociológico quanto florístico. É de se esperar que este novo sistema de campinas apresentado aqui seja também de grande interesse. É preciso, mesmo agora, começar a elaborar um programa racional de conservação e proteção destas campinas, começando com o estabelecimento de um ou vários parques Nacionais na serra do Cachimbo.

\section{AGRADECIMENTOS}

Agradecemos de maneira muito especial a colaboração do $90^{\circ}$ Batalhão de Engenharia e Construção, tanto em Cuiabá quanto na BR163; à $F A B$ (Força Aérea Brasileira) de Cachimbo: à Miramy Macedo e ao pessoal do Centro de Tecnologia da Oniversidade Federal de Mato Grosso. Também agradecemos ao Dr. William A. Rodrigues, Pedro Lisbôa e Anthony Anderson pelas informações, sugestōes e críticas.

\section{SUMMARY}

Some aspects of the vegetation of the Serra do Ca. chimbo along BR-163 are presented here. The soils are basically sand, with sporadic sandstone. The vegetation, till now considered as Cerrado was found to correspond better to the general Campina type. The elements of the vegetation can be described as mixed, as elements of cerrado, Campina, and northern (Rio Negro and Guianas) Savana species were found. 


\section{BIBLIOGRAFLA CITADA}

Askew, G. P.; Montgomery, R, F, \& Searl, P. J.

1970a- Soil landscapes in north eastern Mato Grosso. Geogr. J. 136 : 211-227.

$1970 \mathrm{~b}$ - Interrelationships of soils and vegetation in the savanna-forest boundary zone of north eastern Mato Grosso. Geogr. J. $136: 370$ 376.

1971 - Soils and soil moisture as factors influencing the distribution of the vegetation of Serra do Roncador, Mato Grosso. III Simpósio sobre o Cerrado, pp. 150-160. Univ. Sảo Paulo.

EITEN, G

1975 - The Vegetation of Serra do Roncarior. Biotropica $7(2): 112-135$
LisBôA, P.

1975 - Estudos sobre a vegetaçäo das Campinas Amazônicas. II. Observaçōes gerais e revisão bibliográfica sobre as campinas amazônicas de areia branca. Acta Amazona 5(3) : 211-223.

1976 - Estudos sobre a vegetaçăo das campinas amazônicas, VI. Aspectos ecológicos de Glycoxylon inophyllum (Mart. ex Miq) Ducke (Sapotaceae). Acta Amazonica 6(2) : 193-211.

SOEMRROER, W, G,

1966 - Amazon soils, a reconnaissance of the solls of the Brasilian Amazon region. Centre for Agricultural Publications and Documentation, Wageningen.

TOLEDO, G.

1962 - Aspectos do vale do rio Araguaia. Rev. Bras. Geogr. 24 : $543-563$

(Aceito para publicaçăo em $7 / 12 / 77$ ) 